\title{
The Inaugural Dr. Gamini Jayakuru Oration - 2011
}

\section{Lucian Jayasuriya ${ }^{1}$}

\section{Good Evening, Ladies \& Gentleman}

Our Chief Guest Dr. Ranjabahu Kulasegaram, Consultant Physician, GU and HIV Medicine Guys \& St Thomas' Hospital, London, Dr. Chandrika Wickremasuriya, President Sri Lanka College of Venereologists, Past Presidents, Members of the Council and Members of the College, Dr. Wimal Jayakuru, the daughters of Gamini and Wimal Jayakuru and other members of their family, Dr. Rohantha Jayakuru his brother, and distinguished guests, Ladies and gentleman

I thank the President and the Council of the Sri Lanka College of Venereologists, for asking me to deliver the inaugural Dr Gamini Jayakuru Oration. I consider myself privileged to talk about my good friend and colleague Gamini Jayakuru. Gamini was a good friend and a great gentleman. He is a person who did not hurt anybody. He was a man of integrity. He was strict with himself as with those who worked under him. He trained his juniors to do a good job of work. They are ever grateful to him. He was a giant in the field of Venereology. He was an ardent Buddhist.

\section{The life and times of Dr. Gamini Jayakuru}

In keeping with tradition I will dedicate this inaugural oration to describe and discuss the life and times of Dr. Gamini Jayakuru. Gamini Nihal Jayakuru was born on $15^{\text {th }}$ October 1937. He has his education at Royal College, Colombo and The Faculty of Medicine, University of Ceylon, then the only Medical College in Ceylon.

He qualified MBBS in 1964. He obtained the Diploma in Public Health from the University of Liverpool in 1974. This was during the period when almost all post-graduate qualifications were from abroad and mostly from the United Kingdom.

${ }^{1}$ Founder President, Sri Lanka College of Venereologists
You would notice that it had taken him10 years to obtain post-graduate qualifications. This was the norm during that period. One had to initially work where the Department Health wanted one to work. Then later, once a person chooses a speciality he was sent abroad to get the necessary post- graduate qualifications.Gamini's professional career was in the Department of Health Services.

\section{Career in the government health service}

He had wide experience in paediatrics, obstetrics and gynaecology, ENT surgery, general surgery, general medicine. He was District Medical Officer at Rikiligaskada - which was then a small hospital manned by one doctor. He had his public health experience as $\mathrm{MOH}$ Ampara.

He had worked in the Anti- VD Campaign before he opted for a career in Venereology in 1971, one year after I had opted.

In those days the Department of Health Services called applications for careers. Once a person opts for a career and joins it he cannot change his career. The only exception was to join medical administration. To opt for career in Venereology, it was mandatory that a person had been a Medical Officer of Health for two years. Applications were called, an interview was held and selection made according to the number of vacancies. Once selected, doctors were trained for three months at the Central VD Clinic before being posted as MOIC of a VD Clinic.

From 1971 to 1973 Gamini was MOIC VD Clinic Galle. At that time I was MOIC VD Clinic Kurunegala. At that time our clinics were VD and Skin Clinics. Though we managed dermatology at a 
provincial hospital our training in that speciality was not that great.

\section{The Venereology Scene in 1970s}

The Anti-VD Campaign was started in 1954. It was blessed to have a powerful lady, Dr. E. D. C. Pereira as Superintendent. She was a person who was respected by the Head Office. She was responsible for type-planned VD Clinics in the then type-planned two storeyed OPD Buildings of General Hospitals. These clinics were self- contained units, housed upstairs, with a separate entrance. Gamini and I have worked in these well-organised clinics.

In 1971 when Gamini joined the Anti-VD Campaign, it was a well-managed vertical campaign. That was one reason that attracted both Gamini and me to the Campaign. Dr. W. L. Fernando was Superintendent. He was a soft-spoken disciplined man who expected discipline from us.

There was the Central VD Clinic and 11 full-time VD \& Skin clinics managed by trained medical officers. Please note that there were no untrained medical officers working at VD Clinics. In contrast today we have some untrained medical officers manning some clinics. This is as a result of the $13^{\text {th }}$ Amendment to the Constitution which had been foisted on us. I will come to that again later.

The Central VD Clinics had 6 consultants, including two ladies. Even today we have the same number. The medical officer who managed a full-time VD clinic also conducted a Branch Clinic in a hospital about 20-30 miles away. Part-time clinics were conducted by medical officers trained for two weeks at the Central VD Clinic. Both Gamini and I conducted part-time VD Clinics before we joined the campaign. Maintenance of files and record keeping was excellent at the clinics. We had to send detailed monthly statistics to the Superintendent. The Superintendent produced an Annual Report which was an excellent document.

The Anti- VD campaign had a one-day annual meeting in Colombo. Half the day was on scientific communications and the other on administrative matters. It is during these meetings that I became a friend of Gamini.

The Superintendent visited every clinic annually. The consultant microbiologist also visited us annually. He made sure that our microscopy work was up to standar

\section{Dr Jayakuru's career in Venereology}

To be a specialist in Venereology one had one had to work in Venereology for at least two years, get a Diploma in Public Health and do special work in Venereology for six months abroad. All who had opted for a career were sent abroad through WHO Fellowships or Colombo Plan Fellowships. After obtaining his DPH Liverpool, Gamini worked at St Thomas's Hospital London, where the senior consultant was Dr. C. S. Nicol who was then the Advisor to the Ministry of Health on Genitourinary Medicine.

At St Thomas' Gamini and I met the great friend of the Sri Lanka College of Venereologists, Dr David Barlow who is here with us today. When I met him he was senior registrar. Maybe when Gamini met him, he was a consultant. As a part of his foreign training, Gamini visited VD facilities in India, Burma and Thailand.

\section{Consultant in the UK}

Gamini was locum consultant in UK in 1983-84. He worked at Royal Hallamshire Hospital, Sheffield and at Royal Victoria Hospital, Belfast. Dr. G. R. Kinghorn, Clinical Director and Consultant Genitourinary Physician, Royal Hallamshire Hospital was our Chief Guest at our Second Scientific Sessions in 1997.

\section{Director Anti VD Campaign/ National Sexually Transmitted Diseases and AIDS Control Programme (NSACP)}

For over a decade Dr Gamini Jayakuru headed the Anti-VD Campaign, whose name was later changed to the National Sexually Transmitted Diseases and 
AIDS Control Programme (NSACP) in 1985. This was a period of great service by him to Venereology, to the Department of Health Services and to the country. He was an exemplary leader and motivator.

The early 1980s was a period when the Department of Health Services faced a shortage of doctors. This was badly felt at the Anti VD Campaign which was very short of specialists and dedicated doctors. However, Gamini not only stoically managed it but was able to motivate few to join and stay in the campaign. These motivated persons became consultants in Venereology. Gamini was able to get the support of the hierarchy of the Ministry of Health, including that of Dr. Joe Fernando, Secretary Ministry of Health, who is present here today.

The $13^{\text {th }}$ Amendment to the Constitution severely damaged the vertical campaign. Only the CVDC came under the NSACP and the Director. All other clinics went under the Provincial Health Ministries. The Director lost control over the clinics. Some Provincial Health Ministries appointed untrained medical officers to the clinics. Some would not send these medical officers for training in the centre. The quality of work degenerated and some did not send monthly statistics.

In the latter half of 1990s, we attempted to get the Provincial Health Ministries to hand over the STD Clinics physically situated in the Teaching Hospitals to the NSACP. This was met with little success, only two clinics being handed over up to now. Therefore, some of the problems caused by the $13^{\text {th }}$ Amendment remains today.

\section{Director NSACP}

During his time as Director Dr. Jayakuru was responsible for the following

- The Short Term Plan of Action for Prevention \& Control of STD/AIDS

- The First Medium Term Plan

- The External Review of the Medium Term Plan
- The Interim Plan of Action and The Preliminary Proposal for the World Bank funding of the NSACP

\section{International Consultancies}

Dr Jayakuru was much sought after as an international consultant. He was WHO Short Term Consultant to Nepal, Sudan, Myanmar, Jordan and Iran. He was

- a member of the External Review Team to DPR Korea

- WHO Short Term Consultant at SEARO

Delhi for 6 months and

- a member of the Review Team to evaluate implementation of the UNAIDS programme in India and Myanmar.

\section{Important International Meetings}

He took an active part in many important international meetings. In my slides, I am showing only three of them and talking about one. The most important meeting he took part in was the Expert Committee to Develop Algorithms for the Management of STD, in Geneva in 1990. There, Dr. Jayakuru made a significant contribution on the Syndromic Approach. SriLanka under his leadership had implemented a Syndromic Approach in certain areas of the country.

I think that it is necessary that I explain to some of you what the Syndromic Approach is.

When a patient comes to a STD clinic an attempt is made to diagnose and then treat. For example if a man comes with a discharge from the urethra, a swab is taken and microscopy is done, to get the diagnosis. If it is gonorrhoea he is treated for it, if it is nonspecific urethritis (NSU) he is treated for it.

In many countries the number of STD clinics is not enough.. If a patient with the above symptom comes to a small hospital, what should the doctor there do? Ideally he should refer the patient to an STD Clinic. 
However, most of the time the patients would be reluctant to travel far, to a STD clinic.

The other option is for the doctor to treat the patient for both the common conditions that cause discharge per urethra, namely gonorrhoea and NSU. Of course the patient may get more drugs than necessary, but he gets cured. He will also not be a source of transmission of the disease. This concept was fine tuned at this meeting. Sri Lanka and Tanzania already had flow charts which were used as basic documents.

\section{The Sri Lanka College of Venereologists}

Gamini was a pioneer in the foundation of the College of Venereologists. Few of us including Iyanthi Abeyewickreme and Thiloma Munasinghe realised the need for a scientific body for the speciality. We had many discussions and founded a College, without going through the motions of forming an association and then graduating to a college. We founded the College of Genitourinary Physicians whose name was later changed to the College of Venereologists.

I am very happy that very small group of like-minded dedicated persons were able to organise a college and keep it live and vibrant for 16 years, of course with active participation of all who joined the speciality. Gamini was an active member of the council from the inception in 1995 till his sad demise in 2010. He was the second President of our college.

His Presidential Address in 1998 was on the subject in which he was highly interested. It was on, 'The management of sexually transmitted diseases a etiological diagnosis or syndromic diagnosis.'

\section{Contribution to training in Venereology}

His contribution to training in Venereology was immense. He was a great trainer of doctors who came to work at the CVDC. He taught them not only how to take a history, examine a patient, do the microscopy and make a diagnosis, but also taught them how to keep good records.
He was one of the pioneers who developed the curriculum for the Diploma in Venereology. At this stage, I have to speak about the training pre-1980 and post 1980. It was in 1980 that the Ministry of Health decided to recognise only postgraduate qualifications from the Postgraduate Institute of Medicine (the PGIM).

As I described earlier, pre- 1980, from 1954, trained doctors from the Anti-VD Campaign went abroad and obtained a DPH, DTPH or MPH, did special work in Venereology and came back as specialists. The doctors in the campaign were so well trained that when we went abroad, after a few days at a clinic we were asked to manage patients independently.

There was a separate cadre of specialists in Venereology, separate from the cadre of specialists in public health. In fact at the time Gamini and I returned from abroad we had to apply to be included in the cadre of specialists in Venereology.

\section{Coming to the post-1980 era:}

There was no training programme in Venereology in the PGIM. Doctors who wanted to specialise had to do the MSc in Community Medicine and then the MD in Community Medicine. This was fine for doctors who were already working in the NSCAP. We found that it was possible for a person with little experience in Venereology to get the above qualifications and be a specialist in Venereology. Therefore the College proposed that for the future a specialist in Venereology should have the MD Community Medicine and a Diploma in Venereology.The curriculum of this diploma would also give hands on training.

We were happy when the Board of Study in Community Medicine declined to accept the proposed diploma under its purview. This enabled us to propose the establishment of a Board of Study in Venereology in the PGIM. We were able to get it done rather quickly, with the help of Dr. J. B. Peiris the Director of the PGIM. 
The Board of Study was established in the year 2000 . Gamini was the obvious choice for Chairman. He and Iyanthi as Secretary managed the Board very well. Today we have 63 persons with the Post Graduate Diploma in Venereology, 19 with the MD in Venereology and 03 Board Certified Specialists.

\section{Other interests of Dr Jayakuru}

The two most foremost outside interests of $\mathrm{Dr}$ Jayakuru were the Orchid Circle of Sri Lanka and the Servants of the Buddha. Gamini was an expert on orchids and was once the President of the Orchid Circle. He was an active council member of the Servants of the Buddha for over a decade. They met weekly for lecture discussions and meditation. He was President for over two years and passed away as President.
Gamini was a devoted husband to Wimal and a loving father to his two daughters. He was a pioneer in modern Venereology in Sri Lanka. He worked in Venereology for 40 years

He was a consultant for 35 years. He was Director of the Anti VD Campaign/NSACP for 11 years. He was the first chair of the Board of Study in Venereology.

Ladies and gentleman

Dr. Gamini Nihal Jayakuru was a giant in the field of Venereology in Sri Lanka. We will always remember with gratitude, the great contribution made by this respected gentleman. 